\title{
Citation:
}

Burleson, B. R., Kunkel, A. W., Samter, W., \& Werking, K. (1996). Men's and women's evaluations of communication skills in personal relationships: When sex differences make a difference-and when they don't. Journal of Social and Personal Relationships, 13, 201-224.

\section{Published version:}

http://dx.doi.org/10.1177/0265407596132003

\begin{abstract}
:
Much recent research on gender and communication has emphasized differences in men's and women's communicative conduct, with some theorists going so far as to claim that men and women constitute different cultures. However, comparatively little research has assessed both similarities and differences in men and women's communication to determine whether the sexes are more alike or different. The present paper provides such assessments with respect to men's and women's evaluations of the importance of diverse communication skills in two relationships, friendship and romance. Two studies are reported. In Study 1, participants $(\boldsymbol{N}=382)$ evaluated the importance of eight communication skills in same-sex friendships. Results indicated that although females rated affectively oriented communication skills as somewhat more important than males and males rated instrumentally oriented skills as somewhat more important than females, both males and females overwhelmingly viewed affectively oriented skills as more important than instrumental skills. Study 2 sought to replicate and extend the findings of Study 1 by having participants $(\boldsymbol{N}=685)$ evaluate the importance of eight communication skills for either same-sex friendship or opposite-sex romances. Results virtually identical to those of Study 1 were obtained in Study 2 for both friendship and romance. Findings are discussed in terms of their implications for our understanding of communication in personal relationships and the different cultures perspective.
\end{abstract}

